\title{
Securitização da política pública em Belo Horizonte e redes de financeirização
}

\author{
Public policy securitization in Belo Horizonte \\ and financialization networks
}

Thiago Canettieri [I]

\begin{abstract}
Resumo
0 presente artigo tem como objetivo analisar a formação da coalizão que levou à empresificação da política urbana e à securitização em Belo Horizonte, primeira cidade no Brasil a adotar esse tipo de modelo de gestão urbana, bem como a constituição de uma rede de financeirização das políticas públicas em escala nacional. 0 artigo estrutura-se a partir da análise de documentos da PBH Ativos S/A e da análise das relações que determinados atores desempenham na concepção, na circulação e na efetivação desse modelo de política pública. Sugere-se a existência de uma forma específica de gestão baseada no desenvolvimento urbano-financiado por meio de mercados financeiros.
\end{abstract}

Palavras-chave: políticas públicas; desenvolvimento urbano; capital financeiro; securitização.

\begin{abstract}
The present article aims to analyze the formation of the coalition that led to urban policy corporatization and to securitization in Belo Horizonte, the first city in Brazil to adopt this type of urban management model. In addition, the article examines the creation of a nationwide network for public policy financialization. The article's structure is based on the analysis of documents from the state-owned enterprise PBH Ativos S/A and of the roles that certain actors play in the conception, circulation and implementation of this model of public policy. It suggests the existence of a specific form of management based on urban development financed through financial markets.
\end{abstract}

Keywords: public policies; urban development; financial capital; securitization. 


\section{Introdução}

Observamos, já há algum tempo, o rápido avançar da razão neoliberal sobre as cidades brasileiras, marcada pela disseminação de práticas baseadas no mercado como racionalidade dominante e pela empresa como modelo fundamental de governança (Dardot e Laval, 2016). 0 golpe jurídico-parlamentar-midiático perpetrado contra a presidenta eleita Dilma Rousseff, do PT, em 2016 (mas que vinha se desenhando desde 2014), deve ser lido nesta chave: um inequívoco avanço das forças alinhadas com o projeto neoliberal, já em curso com os governos petistas, mas, agora radicalizados. Isso significou o aumento da exploração, a diminuição das políticas sociais redistributivas, o aprofundamento das desigualdades e a dominação do mercado em todas as esferas da vida. ${ }^{1}$ No Brasil, essas dinâmicas capitalistas neoliberais ganharam mais destaque, atingindo a governança das cidades, envolvendo, por exemplo, a criação da Secretaria Municipal de Desestatização e Parcerias em São Paulo. Para além da adoção de instrumentos urbanos neoliberalizantes no Estatuto das Cidades, como é o caso das Operações Urbanas Consorciadas, outros mecanismos, como a criação de empresas públicas para a realização de Parcerias Público-Privadas - PPPs, têm feito parte das estratégias de ampliação da lógica financeira de produção espacial (Canettieri; Franzoni e Romeiro, 2018).

Nesse sentido, no contexto do programa de pesquisa do INCT Observatório das Metrópoles, desenvolvemos o argumento de uma inflexão ultraneoliberal (Ribeiro e Bógus, 2018) na ordem urbana das cidades brasileiras. Essa inflexão indica um duplo processo de ruptura e continuidade. Se, por um lado, há uma relativa continuidade com relação à agenda neoliberal dos governos petistas entre 2003 e 2016, uma vez que muito dos instrumentos que subsidiam essa política foram regulamentos nessas gestões, assim como ocorreu a consolidação de uma prática estatal orientada pelo mercado; por outro, sinaliza-se uma ruptura em relação a certas dinâmicas anteriores, intensificando a hegemonia da ordem ultraneoliberal, que encerrou um ciclo em que conviveram de maneira concorrente, mas combinada, constituindo um laissez-faire urbano abertamente neoliberal e um regime de reprodução baseado na redistribuição. 0 que acontece, neste novo momento da frágil democracia brasileira, é a radicalização das práticas neoliberais em todos os níveis.

Concomitantemente a esse processo, desde 2013, vem sendo divulgada a recessão econômica que acomete o Brasil. A queda do crescimento, decorrente de variados motivos - globais e locais - tem um impacto direto na queda da receita dos estados e municípios, resultando numa crise fiscal que salta aos olhos, em especial a partir de 2015, mantendo-se entre as manchetes dos jornais. Segundo relatório da Firjan - Federação das Indústrias do Rio de Janeiro (2016), considerando dados do exercício fiscal de 2015 , quase $90 \%$ dos municípios brasileiros estavam à beira da insolvência financeira, com uma situação fiscal crítica, e muitos descumprindo os limites de despesas previstos na Lei de Responsabilidade Fiscal. Considerando o exercício fiscal de 2016, pesquisa encomendada pela CNM - Confederação Nacional dos Municípios (2017) identificou que mais de $60 \%$ dos municípios fecharam o ano no vermelho. A situação delineia-se pela combinação de causas conjunturais e estruturais do capitalismo de crise em seu momento 
neoliberal. A queda da atividade econômica acumulada desde 2015 provocou a desaceleração das receitas.

Esse processo vem absorvendo grande parte dos recursos dos orçamentos estaduais e municipais, afetando a vida de toda a sociedade, que paga a conta por meio tanto dos elevados tributos como dos serviços públicos que deixa de receber. Apesar de pagar a conta, a sociedade não sabe que dívidas são essas, como foram contraídas, onde foram aplicados os recursos, quem se beneficiou deles, qual a natureza dos passivos dos bancos estaduais privatizados que foram transformados em dívida do estado, etc. As condições de refinanciamento impostas pela União aos estados e municípios mostraram-se extremamente onerosas. A cada mês, a dívida é atualizada, e sobre esse montante incidem elevados juros, de forma cumulativa ao longo dos meses. Esse formato fez com que as dívidas se multiplicassem e se transformassem em uma bola de neve. Eis uma forma da acumulação por despossessão em curso (Harvey, 2014).

Dessa maneira, estados e municípios têm se mobilizado para encontrar fontes alternativas de captação de recursos para a gestão pública. Duas saídas principais têm sido adotadas: as chamadas operações de securitização da dívida ativa (uma das principais tendências para os próximos anos em todo o Brasil) e a adoção de parcerias público-privadas para o provimento de políticas públicas. Ou seja, são os municípios buscando novas formas de financiamento.

É, tendo por base esse pano de fundo, que é possível compreender a criação da $\mathrm{PBH}$ Ativos S/A, uma empresa de administração indireta, na forma de sociedade anônima de capital fechado, criada pela prefeitura de Belo
Horizonte por intermédio da lei n. 10.003 (alterações dadas pela lei n. 10.699), de 25 de novembro de 2010, e do decreto n. 14.444 , de 9 de junho 2011. A empresa, conforme descrição em sua página na internet, tem por missão auxiliar a prefeitura municipal de Belo Horizonte na articulação e operacionalização de políticas públicas voltadas para o "desenvolvimento econômico e social do município".

É possível definir os dois principais braços por meio dos quais a PBH Ativos S/A atua: o primeiro deles é a instituição de PPPs. A PBH Ativos pode até atuar como mandatária do município e é responsável por todo o processo, desde a publicação dos termos da manifestação de interesse até a modelagem econômica das PPPs. Seu segundo braço é a instituição responsável pela securitização da dívida do município para adiantar a receita por meio da emissão de debêntures.

Conforme argumentam Peck e Tickel (2002), nesse processo de neoliberalização, estão sendo articuladas etapas de desregulação e o desmantelamento dos marcos institucionais previamente existentes para, em seguida, serem colocados outros modos de governança mais alinhados ao ideário neoliberal em jogo. É exatamente sob essa tendência que observamos o surgimento da PBH Ativos $\mathrm{S} / \mathrm{A}$, como um elemento fundamental para entender a empresificação da política ${ }^{2}$ em curso nesse momento de inflexão ultraneoliberal (Canettieri, 2017).

Com esse termo, pretendemos chamar a atenção para os novos moldes, circunscritos ao ideário do neoliberalismo, em que a política se torna comandada por uma razão própria da empresa, num processo sucessivo de dominação do primeiro pelo último. Assim, empresificação da política designa o vir a ser 
empresa da política, o que representa muitíssimo bem o funcionamento e a razão de ser da $\mathrm{PBH}$ Ativos S/A.

Entretanto, como veremos, esse processo não é uma exclusividade de Belo Horizonte. Muitos outros municípios (e estados) estão adotando o mesmo modelo da PBH Ativos para a gestão de sua política urbana e para o seu financiamento, indicando a empresificação da política. Por exemplo, em 2014, foi criada, em Goiânia, uma sociedade de propósito específico para operar a securitização (lei municipal n. 9.524/2014), e, em 2015, no Rio de Janeiro, a Companhia Carioca de Securitização (lei municipal n. 40.198/2015). O mesmo aconteceu com a iniciativa - barrada pela justiça em Porto Alegre, que criava a Investe POA (lei municipal n. 11.991/2015), assim como em Niterói (lei municipal n. 3.173/2015) e em Santa Rita de Paraíba (Lei municipal n. 1.662/2015).

Mas não ocorreu da mesma forma em Vitória, com a criação do Fundo Especial da Dívida Ativa (lei municipal n. 90/2015), ou em Ribeirão Preto, com o Fundo Especial de Créditos Inadimplidos e Dívida Ativa (lei municipal n. 2.720/2015). Ainda em 2015, Brasília (lei municipal n. 23/2015) autorizou a securitização de parte da dívida ativa. Em Campinas, em 2016, foi criada a PMC-Ativos (lei municipal n. 153/2016), mesmo ano em que o município de Salvador criou sua própria Companhia de Securitização (lei n. 8.961/2016), assim como Florianópolis autorizou o Fundo Especial de Créditos Inadimplidos e Dívida Ativa (lei municipal n. 1.518/2016) e também Guarulhos (lei n. 451/2016).

Uma das primeiras medidas de João Doria, na gestão de São Paulo, foi alterar o estatuto da SP Negócios para permitir a securitização (lei municipal n. 179/2017). Também, em 2017, foi o que se observou em Contagem (lei municipal n. 221/2017). De 2010 até 2017, foram criadas 16 empresas ou fundos semelhantes à PBH Ativos por outros municípios. Estamos vendo se formar um determinado tipo de financiamento do desenvolvimento urbano por meio do mercado financeiro.

Compreender a expansão dessas empresas pelo território nacional pode ajudar a interpretar a inflexão ultraneoliberal que acompanhamos, bem como a empresificação da política (ibid.) em curso. A criação desse tipo de empresa ainda não foi amplamente debatida no contexto dos estudos urbanos.

Nesse sentido, o objetivo expresso neste artigo é analisar a formação da coalizão que levou à empresificação da política urbana em Belo Horizonte, primeira cidade no Brasil a adotar esse tipo de modelo de gestão urbana. Em seguida, segue-se a análise dos atores envolvidos nessa coalizão que circula pelo Brasil e leva esse modelo, construindo, assim, uma rede de financeirização das cidades. É fundamental, para uma compreensão efetiva do atual momento nas cidades, o entendimento dos atores envolvidos na condução desse processo, sua capacidade de agência e os mecanismos adotados por eles para emplacar esse tipo de gestão nas políticas públicas municipais.

Para este trabalho, foi realizado um mapeamento das pessoas responsáveis pela implementação da PBH Ativos S/A e dos gestores envolvidos em suas atividades, objetivando com isso estabelecer os vínculos que esses indivíduos possuíam antes de assumirem cargos na PBH Ativos e quais funções assumiram depois de deixarem a empresa. Esse modelo está sendo aplicado em todo o Brasil e, portanto, 
é preciso entender a "rede" e os seus nós que atuam na financeirização das cidades para que se possa elaborar uma crítica a esse modelo de gestão.

Para tanto, adotamos uma estratégia de pesquisa descrita por Peck e Theodore (2015): a following policies. Basicamente, trata-se de acompanhar o desenvolvimento e as reformas institucionais e dos marcos legais e jurídicos, além dos atores de influência, para que se possa criar condições para que essas políticas "aterrissem" em determinados locais, permitindo, assim, entender a transferência de políticas públicas cada vez mais market-friendly, construindo um consenso para a empresificação da política pública sob a sombra dos interesses de frações do capital financeiro. Dessa maneira, pretende-se elucidar os regimes urbanos e as suas estratégias para aplicar esse corolário - pauta do capital financeiro já adotada amplamente em países como Estados Unidos e Canadá (Peck e Whiteside, 2016). Esta pesquisa contribui na fundamental parte de identificar, analisar e qualificar o regime urbano específico da gestão empresarial da política urbana (Canettieri, 2017).

Este artigo apresenta a empresificação da política pública tendo por base a $\mathrm{PBH}$ Ativos S/A realizada em Belo Horizonte durante a gestão de Márcio Lacerda, abordando as principais atividades da empresa para, em seguida, tratar da estratégia de captação de recursos por meio do mercado financeiro. A partir daí, será apresentada a coalizão que se formou em Belo Horizonte para o desenvolvimento, funcionamento e consolidação desse tipo de política. Em seguida, expomos a discussão em torno da transferência de políticas públicas entre localidades para abordar, especificamente, a velocidade diferencial que algumas políticas recebem na sua difusão em contraste com outras. Por fim, discutiremos a formação da rede de financeirização que está se formando, apontada como uma tendência para as futuras gestões públicas. Finalmente, discutimos os impactos desse modelo, bem como apontamos para uma agenda de pesquisa futura sobre esse tema.

\section{Empresificação da política pública e a PBH Ativos}

A criação da PBH Ativos pela gestão do ex- prefeito de Belo Horizonte, Márcio Lacerda, tinha por objetivo que ela fosse uma empresa capaz de auxiliar a prefeitura municipal na articulação e na operacionalização de políticas públicas voltadas para o desenvolvimento econômico e social do município, por intermédio: 1) da gestão de obras de infraestrutura; 2) da instituição de parcerias público-privadas; 3 ) da captação de recursos financeiros; 4) da administração patrimonial; e 5) da gestão de ativos e de imóveis. Assim, ela é definida nos termos da legislação referente ao objeto social com a finalidade de:

1) titular, administrar e explorar economicamente ativos municipais;

2) auxiliar o Tesouro municipal na captação de recursos financeiros, podendo, para tanto, colocar no mercado obrigações de emissão própria, receber, adquirir, alienar e dar em garantia os ativos, créditos e valores mobiliários da sociedade; estruturar e implementar operações que visem à obtenção de recursos junto ao mercado de capitais; 
3) auxiliar o município na realização de investimentos em infraestrutura e nos serviços públicos municipais em geral;

4) auxiliar o município na atividade de conservação e manutenção de seus bens; auxiliar o município em projetos de concessão ou de parceria público-privada, podendo, para tanto, dar garantias ou assumir obrigações;

5) licitar e/ou realizar obras mediante celebração de convênio ou contrato com os órgãos ou as entidades da administração direta ou indireta do município, salvo no caso de suas obras serem destinadas à valorização dos seus próprios ativos;

6) auxiliar, gerenciar ou realizar obras licitadas por outros órgãos ou entidades da administração direta e indireta do município, nas quais, sempre que possível, venha a ter ganho econômico;

7) custear obras licitadas por outros órgãos ou entidades da administração direta ou indireta do município.

0 descrito no decreto $n$. 14.444 demonstra em quais limites a empresa PBH Ativos vai atuar, e o que se constata é a violenta entrada na prática pública do município. Ao titular, administrar e explorar economicamente os ativos da prefeitura, primeiro "objeto social", a empresa irá gerar riqueza tendo por base recursos públicos, investindo ou deixando de investir, orientada apenas pelas necessidades impostas pela lógica do lucro. E, quando se descreve seu "auxílio", seja para gerenciar ou para realizar obras licitadas ou de infraestrutura e de serviços urbanos, a própria lei complementa: "sempre que possível venha a ter ganho econômico". Fica claro, ainda, o movimento contemporâneo de articulação do capital financeiro com a prática da política municipal, quando se delimita o auxílio à captação de recursos financeiros no mercado, girando, assim, o sistema de dívida, e o público assume todos os riscos, inspirado em moldes fadados ao fracasso, como no caso da Grécia.

Uma literatura crítica desenvolveu-se em torno dessas práticas, explorando as contradições e os impactos que representam à vida social. Todavia, cabe levar em consideração que essa prática é própria da natureza do capitalismo contemporâneo, que se conforma dentro dos marcos do neoliberalismo econômico.

É possível argumentar que a $\mathrm{PBH}$ Ativos S/A representa um constante processo de fluxo de dinheiro público para o âmbito privado, estratégia esta descrita por Harvey (2004) como própria do neoliberalismo. Ainda nesse âmbito, surgem inúmeras formas de inovações financeiras (como os derivativos nos mercados de opções e futuros que permitem a comercialização do direito de compra ou venda de determinado ativo financeiro, por determinado preço, em determinada data futura, abrindo a possibilidade de investidores se protegerem de eventuais dinâmicas de desvalorização abruptas, mas, ao mesmo tempo, criando campo para a atuação de capitais especulativos agressivos) com a utilização de instrumentos de securitização e de dívidas transformadas em ativos financeiros comercializáveis. Assim, o capital tem encontrado variadas formas de garantir sua reprodução por intermédio de vários malabarismos jurídicos, legislativos e financeiros.

É, nesse contexto, que se insere a formulação de Harvey (2013) referente aos processos de financeirização da produção capitalista. 0 autor procura deixar claro que, no processo de reprodução ampliada do capital, os juros devidos ao crédito (bem como o lucro do capitalista) são derivados diretamente do 
mais-valor obtido sobre o processo de trabaIho. Por mais que o capitalista monetário atue num circuito direto de $D-D^{\prime}$, o processo de sua remuneração via juros ocorre somente porque acontece a apropriação de mais-valor.

Insere-se nesse cenário, portanto, a remuneração dos debenturistas da PBH Ativos. Eles recebem parte do mais-valor gerado pela empresa na forma de juros. Segundo os comunicados aos debenturistas da PBH Ativos, são transferidos valores da ordem de 5 milhões e meio de reais como pagamento das parcelas de amortização, juros e atualização monetária do empréstimo.

De tal maneira, parte da política urbana do município realiza-se, desse modo, a partir da PBH Ativos e não, necessariamente, da prefeitura. Por meio do decreto n. 15.534, de 2014, a PBH Ativos começou a atuar na Secretaria de Desenvolvimento, auxiliando a prefeitura em investimentos de infraestrutura, em serviços públicos municipais, dentre outros. $O$ decreto aumentou as prerrogativas da empresa na administração municipal. Os custos financeiros das operações de debêntures de pagamento de juros e a remuneração dos seus investidores são cobertos pela PBH Ativos. Mas, para isso, seu "negócio" deve dar lucro. Sendo assim, o objetivo da política pública urbana é revertido para a remuneração de investidores privados, mesmo que se saiba, tendo por base vasta literatura, que a intenção de lucro e o "bem-estar da população" (que deveria ser o objetivo de uma política pública) possam seguir caminhos bem diversos.

Segundo o texto que institui a empresa $\mathrm{PBH}$ Ativos S/A, esta deverá atuar em todas as PPPs que o município solicitar por meio do seu Conselho Gestor das Parcerias Público-Privadas. São previstas PPPs para o mercado distrital do Cruzeiro; para o Centro de Convenções de Belo Horizonte; para o Terminal Rodoviário Municipal; para a iluminação pública; para vilas produtivas e supermercados; para estacionamentos e para a gestão dos rotativos do futuro Centro Administrativo Municipal; para cemitérios, no Novo Sistema de Mobilidade Urbana Compartilhada; para parques, como o Parque Mangabeiras; para o Jardim Zoológico; para o Jardim Botânico; para o Parque Ecológico; e para o Parque Barragem Santa Lúcia. Além do que já está previsto, o comunicado existente no site da empresa afirma que ela já vinha atuando nas PPPs do município, oferecendo garantias a empreendimentos, como o Projeto Inova (construção de escolas municipais em parceria público-privada com a Odebrecht) e o projeto do Novo Hospital Metropolitano.

Dessa forma, a questão da política urbana municipal de Belo Horizonte fica condicionada aos lucros dessa empresa. Com essa forma de desenvolvimento que ocorre com a integração entre capital financeiro e as políticas públicas, volta-se para uma orientação que segue a lógica do lucro, priorizando-se os mecanismos de valorização do capital e não necessariamente $\mathrm{o}$ atendimento dos serviços e das políticas públicas (Canettieri, 2017).

\section{A crise fiscal e a captação de recursos de financiamento por mercados financeiros: securitização da dívida ativa}

Estados e municípios têm se mobilizado para encontrar fontes alternativas de captação de recursos para a gestão pública. As principais 
saídas têm sido as chamadas operações de securitização de dívida ativa, que têm se tornado uma das principais tendências para os próximos anos. Essa captação via mercado de capitais é o que aconteceu em Belo Horizonte com a PBH Ativos S/A.

Entretanto essa prática não é nossa jabuticaba, uma exclusividade brasileira. Na verdade, esse tipo de política já é adotado, desde a última década do século XX, nos Estados Unidos, e, agora, já é possível começar a mensurar as consequências e implicações dessa prática, como fazem Peck e Whiteside (2016). Os autores demonstraram como esse processo tem sido amplamente empregado em cidades dos Estados Unidos, como Boston e Detroit. "O regime da governança urbana nos Estados Unidos tem sido financeirizado de maneira mais intensa do que nunca" (ibid., p. 238; tradução nossa). Diante da crise fiscal pela qual os municípios passam em todo o mundo, uma das saídas mais recorrentes tem sido a aplicação do plan of adjustment, que significa a captação de recurso no mercado de capitais sob a forma de dívidas emitidas para investidores. Com o volume de dinheiro auferido com a compra desses papéis, o poder público tornar-se-ia apto a realizar as obras e a gestão dos serviços públicos. 0 resultado observado pelos autores é o "padrão prevalecente de governança urbana cada vez mais baseado em lógicas financeirizadas e práticas tecnocráticas" (ibid., p. 237; tradução nossa).

Desde a passagem para o século XXI, economistas vinculados ao Fundo Monetário Internacional (FMI) têm discutido, internacionalmente, a securitização como resposta para a crise fiscal - em especial para emerging markets. No dia $11 \mathrm{de}$ junho de 2003, foi emitida, pelo FMI, uma proposta: Assessing public sector borrowing collateralized on future flow receivables ${ }^{3}-$ um modelo muitíssimo semelhante ao que estamos tratando aqui. Em seu canal de notícias, o FMI divulgou, no dia 21 de setembro de $2003,{ }^{4}$ uma notícia com a manchete destacando a securitização como uma saída para a crise fiscal. Em 2006, um economista do FMI do departamento de mercado de capitais publicou um working paper sobre a securitização em emerging markets. A crise financeira de 2008/2009 foi impulsionada pela securitização das hipotecas subprimes (Christophers, 2011), e, mesmo com a magnitude dessa crise, as orientações das instituições financeiras continuavam a insistir na securitização. Em 2009, foi lançado, pelo FMI, o livro The new public finance, que apresentava a securitização como responding to global challenges. Em 2013, a seção Working Paper do FMI emitiu uma espécie de balanço das práticas com o documento Securitization: lessons learned and the road ahead. ${ }^{5}$ Em janeiro de $2015,{ }^{6}$ no site do FMI, foi divulgado um survey demonstrando como a securitização foi utilizada para gerar crescimento e estabilidade financeira. Troan (2015) analisa como muito rapidamente os papéis de securitização voltaram a circular na economia norte-americana, como os referentes às dívidas estudantis. Eis a natureza do capitalismo contemporâneo: comprar tempo para adiar a crise vindoura (Streek, 2018).

Parece haver, portanto, um consenso nos modelos de governança em escala global e que se empenha para aplicá-los localmente. Por isso, entender a rede de atores que atuam na efetivação desse tipo de política pública ajuda em muito na compreensão de seus próprios 
mecanismos. Em especial, é necessário entender o arranjo dessa coalizão, pois, como visto, esse modelo tem se espalhado no Brasil como forma de política pública.

Foi essa a mesma medida adotada pelo governo de Márcio Lacerda, em 2010, com a criação da empresa de administração indireta PBH Ativos S/A, em que se previa a estruturação e a franca utilização desse tipo de operação pelo município de Belo Horizonte. Passou-se, dessa forma, a ser mobilizada a dívida ativa do município, composta por créditos predominantemente de natureza tributária que não foram quitados, como lastro para a emissão de papéis no mercado financeiro para, dessa forma, conseguir o adiantamento de receita. Nessa operação de securitização, portanto, o que ocorre é a cessão de créditos da dívida ativa a um agente securitizador que emite para investidores anônimos valores mobiliários cujos pagamentos estarão vinculados ao recebimento desses créditos.

O objetivo com essa operação é garantir, ao ente federado, a liquidez necessária para as contas públicas, uma vez que os investidores pagam à vista pela cessão desses créditos.

Assim sendo, o ente federado que precisa do recebimento adiantado vende essas dívidas no mercado de capitais e recebe, do investidor, o valor adiantado; por sua vez, o investidor não faz tal operação por benevolência. 0 próprio termo adotado - investidor - prevê que ele deve auferir ganhos nessa operação. Sobre esses papéis incidem juros, pois seu investimento deve ser remunerado condizentemente, num mercado de capitais cada vez mais financeirizado e competitivo (Alvarenga, 2018).

Este tem sido um dos principais novos mecanismos de financiamento das políticas públicas e do desenvolvimento urbano, apelando para o financiamento pelo mercado financeiro como forma de subsidiar contas nesse momento de crise fiscal.

0 processo de securitização da dívida ativa municipal é vedado por lei, caso realizado pelo município - diferentemente do caso dos Estados Unidos, como Peck e Whiteside (2016) demonstram. Como consta na Lei de Responsabilidade Fiscal (lei federal n. 101/2000) e na própria Constituição Federal, esse tipo de pacto social coloca em risco a democracia, como destaca em sua análise sobre a disseminação dessa prática a auditora fiscal Eulália Alvarenga (2018). Ou seja, esse tipo de prática não passaria de uma "pedalada" para driblar essas leis (Fattoreli, 2017).

A PBH Ativos S/A apela para um artifício comum aos esquemas financeiros: o sistema da dívida pública. Essa engenharia adota o modelo da securitização da dívida ativa dos municípios, propagandeada pelos ideólogos do neoliberalismo como a solução possível e rentável para a crise fiscal dos entes federados e como forma de obter recursos em operações no mercado financeiro. 0 que acontece, na contramão da promessa neoliberal, é que tais operações - feitas, como no caso da PBH Ativos - correspondem à geração e ao aumento da dívida pública.

Essas empresas servem de fachada para que o ente federado faça uma operação de crédito disfarçada, extremamente onerosa, obtendo recursos no mercado financeiro graças à venda de derivativos financeiros com garantia pública - disfarçados de debêntures sênior - oferecidos ao mercado com remuneração exorbitante. A elevada remuneração oferecida pela empresa está sendo paga com recursos arrecadados dos contribuintes, 
por meio de créditos tributários e não tributários que foram parcelados. Essa prática disfarça o efeito de maior endividamento, sendo ilegal e inconstitucional, além de extremamente onerosa ao município, comprometendo o patrimônio público. Em suma, o lançamento de derivativos financeiros a serem negociados no mercado de capitais com juros extremamente vantajosos e com garantia pública custa demasiado caro. 0 município assume esse compromisso com uma remuneração exorbitante expressa no contrato, comprometendo o patrimônio público, que é destinado aos pagamentos dos rendimentos dessas dívidas, o que, de fato, não cumpre a promessa de eficiência econômica e austeridade dos gastos públicos.

No caso em questão, títulos lastreados e derivados dos créditos tributários a receber do município de Belo Horizonte são lançados no mercado financeiro sob a forma de debênture, vinculando o patrimônio público à remuneração de capitais especulativos. Essa é a lógica de securitização da dívida ativa do município: transformar direitos creditórios que deveriam ter destinação social em produto financeiro. A justificativa corrente utilizada pela gestão municipal de Márcio Lacerda e seus secretários, legitimada por parte da imprensa, é a de que se trata de uma necessidade diante da crise fiscal e orçamentária dos municípios, sendo, então, necessário o adiantamento de dinheiro para a realização de obras públicas. Entretanto, como veremos, essa lógica vem, na verdade, a ampliar a dívida pública do município, uma vez que os contratos oferecem aos investidores-debenturistas uma taxa de remuneração significativa que, portanto, onera os cofres públicos. Dessa forma, a engenhoca de dívida criada pode impactar na destinação dos recursos públicos e, portanto, transformar, também, as políticas públicas, podendo alterar a dinâmica territorial do município e a vida cotidiana da população.

A alternativa construída pelos gestores de Belo Horizonte foi a criação da empresa estatal não dependente, a PBH Ativos S/A, que realizaria esse processo emitindo papéis financeiros, como as debêntures, para investidores do mercado de capitais. Dois tipos de debêntures são emitidas: a primeira é a subordinada, fazendo referência a títulos entregues pelo ente federado como forma de oferecer a garantia, por meio de patrimônio público, para a segunda emissão. Essa segunda emissão é de debêntures sênior, com garantia real, vendidas para investidores privilegiados a índices elevados de juros remuneratórios. A garantia do pagamento desses juros é dada pelo ente federado. Com isso, o rating, ou seja, a classificação dessa operação para os investidores, é avaliado como "retenção de riscos e benefícios", um investimento atrativo de baixo risco e, acima de tudo, bastante lucrativo.

O município de Belo Horizonte experimentou, entre os anos de 2010 e 2014, um crescimento constante da Dívida Consolida Líquida do município, bem acima da Receita Corrente Líquida, resultado de um período de crise financeira, causando um aumento, tanto dos juros quanto da amortização, e resultando na elevação da dívida municipal (Hamada et al., 2019). A emissão de debêntures tem por objetivo ampliar a receita corrente líquida do município, a partir da captação de recursos no mercado financeiro, uma forma de alavancagem. A primeira emissão de debêntures realizada pela PBH Ativos S/A captou, no mercado de capitais, cerca de 200 milhões de reais a custo de securitizar 880 milhões de reais da dívida ativa do município (Canettieri, 2017). 
Para fins de comparação, o balanço orçamentário do município, no ano de exercício de 2014, fechou com um déficit de 197 milhões de reais. A captação de recursos por meio do mercado financeiro, como é feita pela PBH Ativos, parece uma ótima operação para o município e o seu gestor de plantão. Os recursos chegam rapidamente e podem ser mobilizados para a criação de obras públicas. Contudo, quais são as implicações dessa operação de securitização da dívida ativa pública? Embora apareça como oportunidade de captação de recursos para efetivar obras e a gestão eficiente do município, as análises têm demonstrado um enorme processo de dilapidação do patrimônio público para pagamento dos debenturistas, com taxas altamente abusivas (IPCA+11\%) de rendimentos a partir de patrimônio público e da gestão das políticas.

\section{A coalizão da empresificação da política em Belo Horizonte}

Para Peck e Theodore (2015) e para a tradição dos regimes urbanos, é necessária a consolidação de uma coalizão de agentes capazes de emplacar com êxito um determinado tipo de governabilidade. Identificar os atores que concentram o know-how, representam determinados interesses e levam uma determinada tecnologia de governabilidade é uma condição fundamental para compreender os arranjos da produção social do espaço. Mesmo com os arranjos mais embrionários, seja por falta de informação, seja pelo caráter incipiente desse tipo de pesquisa, já é possível esclarecer alguns elementos cruciais. Dessa maneira, utilizar a noção de coalizão pode ajudar a compreender a rede de atores na produção da empresificação da política.

O termo coalizão é caro à literatura referente aos estudos dos Regimes Urbanos. Para nos remetermos à definição usada por essa tradição (Massardier et al., 2016), podemos dizer que se trata de uma congregação de determinados atores públicos e privados que se forma para desenvolver, aplicar e difundir um determinado tipo de política, e que é constituída por grupos em várias escalas, ${ }^{7}$ compostos por atores que circulam em diferentes esferas e setores. As coalizões, deve-se ter em conta, são desenvolvidas por intermédio da mobilização que determinados atores sociais conseguem empreender na sua esfera de influência em torno de um determinado assunto de governo.

Já vimos que a $\mathrm{PBH}$ Ativos S/A, mesmo com sua timidez nos primeiros anos de funcionamento, tem se tornado uma tendência para uma nova forma hegemônica de financiamento do desenvolvimento urbano, buscando recursos no mercado financeiro, forma esta que tem sido estendida para outras cidades. Mas, para que isso fosse possível, foi necessário um arranjo de agentes (players) com know-how e uma rede de contatos para fazer funcionar.

É com base nessa chave que se desenvolve a análise a seguir. No Quadro 1, apresentamos os diretores-presidentes e o criador da PBH Ativos. Eles são os responsáveis pela gestão da empresa e pelas práticas adotadas por ela.

0 primeiro ponto a se destacar é a relação que todos possuem com algum banco, o que, por si só, já dá pistas para entender a atual aproximação do governo com o capital financeiro. Inclusive, deve-se destacar que metade deles já teve alguma relação com o 
Quadro 1 - Atores envolvidos na PBH Ativos S/A

\begin{tabular}{|c|c|c|}
\hline Ator & $\begin{array}{l}\text { Período envolvido } \\
\text { na PBH Ativos }\end{array}$ & Antes e depois \\
\hline Márcio Lacerda & $\begin{array}{c}\text { Prefeito de Belo Horizonte } \\
(2009-2012 \text { e } 2013-2016)\end{array}$ & $\begin{array}{l}\text { Presidente da Frente Nacional de Prefeitos e prefeito } \\
\text { de Belo Horizonte que propôs a criação da PBH Ativos, } \\
\text { com passagem pela Cemig, pela Codemig, pelo BDMG } \\
\text { e pelo Instituto de Desenvolvimento Integrado de } \\
\text { Minas Gerais }\end{array}$ \\
\hline José Afonso Bicalho & 2010-2013 & $\begin{array}{l}\text { Primeiro diretor-presidente da PBH Ativos; } \\
\text { ex-presidente do Banco de Crédito Real de MG e do } \\
\text { Bemge; ex-assessor do Ministério do Desenvolvimento, } \\
\text { Indústria e Comércio e do BNDES; e ex-secretário de } \\
\text { Finanças de Belo Horizonte }\end{array}$ \\
\hline Edson Ronaldo Nascimento & 2013 & $\begin{array}{l}\text { Ex-coordenador de finanças do Ministério do } \\
\text { Desenvolvimento, Indústria e Comércio Exterior; } \\
\text { ex-presidente da PBH Ativos, com passagem pelo FMI } \\
\text { e pela Secretaria de Fazenda de Goiás e do Tocantins }\end{array}$ \\
\hline Marcello Piancastelli & 2013-2016 & $\begin{array}{l}\text { Ex-presidente da PBH Ativos S/A; ex-coordenador } \\
\text { tributário da Secretaria de Fazenda de Minas Gerais; } \\
\text { ex-coordenador-chefe do Ministério do } \\
\text { Desenvolvimento, Indústria e Comércio Exterior; } \\
\text { ex-consultor do FMI }\end{array}$ \\
\hline Pedro Meneguetti & 2016 - atualmente & $\begin{array}{l}\text { Atual diretor-presidente da PBH Ativos, com passagem } \\
\text { pela Secretaria de Fazenda de Minas Gerais e do } \\
\text { Distrito Federal, pelo BDMG e pela Secretaria de } \\
\text { Finanças de Belo Horizonte, atuando também no Banco } \\
\text { de Brasília S/A }\end{array}$ \\
\hline
\end{tabular}

Fonte: dados da pesquisa.

FMI, que é conhecido pelo desenvolvimento de cartilhas para o desenvolvimento urbano, "oferecidas" como condição para várias das linhas de crédito. Poderíamos suspeitar que a securitização da dívida ativa municipal faça parte desse mesmo esquema.

0 nome desse fenômeno pode ser carrossel da financeirização. Os atores envolvidos na PBH Ativos (ex e atuais gestores) passaram por vários outros cargos de administração pública ou por órgãos e bancos estatais, além de terem passado por empresas (como consultorias) privadas, em que foi possível a construção do consenso em torno desse modelo de gestão por meio da securitização.
É possível observar, de fato, um certo carrossel: esses agentes, além de passarem pela própria Secretaria de Fazenda de Belo Horizonte, passaram pela do Estado de Minas Gerais e pela do Distrito Federal. Essas duas também passaram a adotar o modelo de securitização. Foi exatamente durante a presença de Pedro Meneguetti na Secretaria de Fazenda de Minas Gerais, durante o governo de Antonio Anastasia (PSDB), que foi alterado o estatuto da companhia MGi para autorizar a securitização. Novamente, foi durante a presença de Meneguetti na Secretaria de Fazenda do Distrito Federal, em 2015, que foi autorizada a criação de uma SPE (Sociedade de Propósito 
Específico) para a securitização. Também Edson Ronaldo Nascimento, na oitiva na Comissão Parlamentar de Inquérito para a que foi convidado no dia 17 de julho de 2017, confirmou que passou pela Secretaria de Fazenda de Goiás e do Tocantins e que lá praticou o que aprendeu na PBH Ativos como forma de "sair da crise fiscal pela qual os estados passavam". Edson Ronaldo Nascimento também oferece cursos sobre a venda de créditos tributários com a consultoria Abba.

O curso será ministrado pelo professor Edson Ronaldo Nascimento, ex-presidente da PBH Ativos S.A. e por profissionais da área de Direito que participaram dessas operações na cidade de Belo Horizonte. ${ }^{8}$

Ainda faltam informações para serem apuradas e um maior esforço de pesquisa em torno desse assunto. Por ora, a hipótese de formação de uma rede de financeirização das práticas governamentais no Brasil parece se confirmar como um tremendo esforço para que a securitização emplaque como prática de gestão que, como já foi visto, favorece a remuneração dos capitais portadores de juros.

\section{Fast-policies e a transferência de políticas}

A literatura referente à pesquisa sobre a formação de políticas públicas e sua transferência e difusão é, em geral, restrita ao campo da ciência política. Essa abordagem começou a se desenvolver, sobretudo, nos países anglófonos, na década de 1960, e foi recolocada em questão no final dos anos 1990. Nessa análise, o objetivo era entender como ocorria a difusão de políticas inovadoras e dispositivos legislativos e jurídicos através das fronteiras, primeiro no contexto de um mesmo país e, em seguida, internacionalmente (Pierre, 2014; Benson e Jordan, 2011; Dolowitz e Marsh, 1996 e 2000).

Segundo a bibliografia, é consenso que um dos fatores determinantes para o sucesso ou o fracasso dessas transferências se refere à capacidade de formação de arranjos em determinados lugares que possam ser usados em outros (Dolowitz e Marsh, 1996, p. 344). Ou seja, esses arranjos permitem que o conhecimento sobre as políticas públicas, a administração e a dimensão institucional circulem pelo território se plasmando - com maior ou menor grau de diferenciação do original -, de acordo com uma capacidade organizativa dos agentes envolvidos.

Esse interesse de pesquisa ganha novos contornos com o trabalho dos geógrafos Peck e Theodore (2015). ${ }^{9}$ Observando o contexto político dos Estados Unidos, os autores ressaltam que há "velocidades diferentes para políticas diferentes". Os autores observam que algumas são fast-policies, e outras têm uma difusão mais lenta. O porquê dessa diferença, escrevem os autores, está no arranjo político que se forma. E mais, eles atentam para o fato de que, nesse momento do capitalismo contemporâneo, as políticas market-friendly são aquelas com a maior força de difusão, uma vez que o regime que emplaca essas pautas está mais fortalecido na conjuntura - sobretudo de crise fiscal.

Portanto, não é estranho perceber, como fazem Peck e Theodore (ibid., p. 48), que existem determinados "laboratórios para experimentações de políticas públicas". 
Caso sejam bem-sucedidas, elas começam a circular; caso fracassem em seus objetivos, podem ser ou não repetidas em outras condições. Os autores chamam a atenção para os agentes responsáveis por "forjar" tais consensos: redes de experts técnicos (como think thanks) e um regime de governança específico. O ponto seguinte, então, está em perceber que a delimitação sobre a definição do experimento, os critérios de sucesso e fracasso, de quando e onde experimentar e por onde seguir dizem respeito, sobretudo, a uma escolha que é, em última instância, uma escolha política, constituída por um determinado arranjo específico de atores que acreditam, promovem ou se opõem a determinadas posturas. Dessa forma, esses atores parecem desenvolver um certo consenso por meio de redes para que se possa efetivar a política pública dentro de determinados moldes previstos.

Como lembram Peck e Theodore (2010, p. 172), "essas redes são construídas na base de conexões entre aqueles que desenham as políticas e as instituições", destacando que, muitas das vezes, guardam uma aproximação com aquelas ligadas ao "negócio da consultoria de políticas públicas".

As estratégias, para tanto, são várias. Elas se valem de exércitos de consultores externos e de defensores das políticas de contratação de determinadas agências para pareceres e pesquisas, da divulgação de uma determinada cartilha, de audiências públicas para convencimento direto ou de gastos com marketing. É o que Peck (2002, p. 352) chamou de transferability packages - um pacote de inovações políticas, ideológicas e institucionais para que se permita a circulação rápida dessas políticas. Mas é importante, e vale a insistência, que os agentes de persuasão muitas vezes se arranjem em redes com determinados interesses e não se limitem a uma emulação tecnocrática, e configurem uma prática política de interesses específicos.

Nesse sentido, Peck e Theodore (2015, p. 223) afirmam:

os campos de política rápida compreendem muito mais do que uma zona de transações bilaterais; eles são compostos de densas redes de relações hierárquicas e laterais e de múltiplos nós de tradução e reinvenção.

É fundamental ter em conta que o processo de difusão e transferência de políticas é, portanto, profundamente contraditório, o que acaba resultando, muitas vezes, em arranjos institucionais frágeis nas primeiras experiências e que, a depender dos interesses, vão se tornando mais robustos. Para isso, não é possível ignorar a capacidade de agência dos atores envolvidos nas práticas de difusão.

0 retrato desses atores é descrito por Peck e Theodore (2015, p. 222):

Muitos dos intermediários e interlocutores mais bem-sucedidos nesses mundos de política rápida são, eles próprios, atores carismáticos e empreendedores experientes. Eles são bem-sucedidos em parte porque são cosmopolitas envolventes e eloquentes. Eles estão armados com roteiros bem-polidos e um excesso de evidências de apoio; eles são persuasores talentosos.

A eficiência e a assertividade dos regimes urbanos se referem, então, à capacidade de convencimento do grupo desses atores e às inovações institucionais que promovem para definir os rumos da governabilidade e do desenvolvimento urbano. 


\section{As redes de financeirização da gestão urbana no Brasil}

O início da prática de securitização deu-se no estado de São Paulo, sob o governo de José Serra (PSDB), no ano de 2009. Por meio da autorização efetivada pela lei estadual n. 13.723, de 29 de setembro de 2009, de proposição do Executivo, constituiu-se a CPSEC (Companhia Paulista de Securitização), uma sociedade anônima controlada pelo estado. Logo em seguida, entre 2010 e 2011, os tucanos de Minas Gerais, durante o governo de Antonio Anastasia, alteraram o estatuto da MGi, empresa ligada à Secretaria de Fazenda do Estado, para que se permitisse também a securitização da dívida ativa do estado.

O estado seguinte a adotar o modelo de securitização, sob o governo de José Siqueira Campos (DEM), foi o Tocantins, que criou um Fundo Especial de Incremento à Arrecadação por meio da Dívida Ativa do Estado. Em 2015, por meio da lei n. 559/2015, o governo carioca, chefiado por Pezão (PMDB), autorizou a criação de uma sociedade de propósito específico para a securitização; o mesmo foi feito pelo decreto n. 897/2015 do Distrito Federal, com o governo de Rodrigo Rollemberg (PSB). Já Goiás, por sua vez, criou a empresa Goiás Parcerias para a mesma atividade, por meio da lei n. 18.837/2015, quando Marconi Perillo (PSDB) estava no cargo executivo.

Em 2016, aconteceram outras duas investidas. Em Piauí, foi autorizada a criação de um Fundo Especial de Créditos Inadimplidos e a Dívida Ativa do Piauí, por meio da lei n. 6.823, para que fosse possível a securitização. 0 governador responsável era Wellington Dias (PT).
No governo da Bahia foi criada, por intermédio da lei n. 13.594/2016, a Bahiainveste - Empresa Baiana de Ativos, com Rui Costa (PT).

Existem notícias que indicam que o mesmo tipo de operação está sendo montado em Mato Grosso e em Mato Grosso do Sul. Entretanto ainda não estão completamente desenvolvidos os instrumentos para que se possa realizar essa operação.

Em seguida, segue-se o mapa dos estados que possuem empresas aptas para a securitização (Mapa 1), incluindo Mato Grosso e Mato Grosso do Sul, que ainda estudam a adoção desse tipo de operação, totalizando dez unidades da federação.

Mas essa prática, que se tornou uma forma de manutenção da saúde financeira dos estados, mesmo com todos os riscos envolvidos e os danos já conhecidos, alcança a escala do município, como em Belo Horizonte, responsável pela primeira experiência desse tipo com o governo de Márcio Lacerda (PSB), com a criação, por meio da lei n. 10.003/2010, da $\mathrm{PBH}$ Ativos S/A. Esse modelo, de 2014 até hoje, expandiu-se até alcançar outros 16 municípios.

É importante notar que a securitização na escala municipal tem um padrão espacial muito mais abrangente, alcançando mais estados. Em geral, são capitais estaduais que adotam essa medida. Entretanto, vale notar que, por exemplo, esse modelo vem sendo adotado em quatro municípios, no estado de São Paulo, seguido por Minas Gerais e Rio de Janeiro, cada um com duas cidades adotando o modelo.

No caso das cidades, a distribuição de partidos é ainda mais dispersa, mostrando uma estrutura de financiamento das atividades por meio do mercado financeiro que parece 
Figura 1 - Mapa de estados nos quais houve criação de empresas de securitização

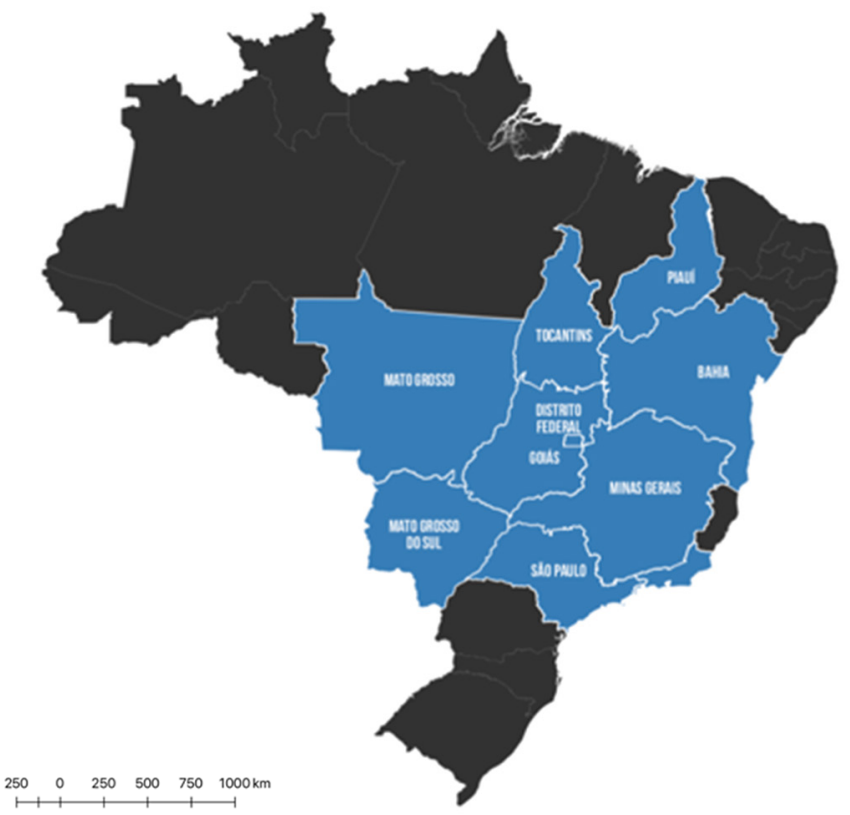

Figura 2 - Mapa de municípios nos quais houve criação de empresas de securitização ${ }^{10}$

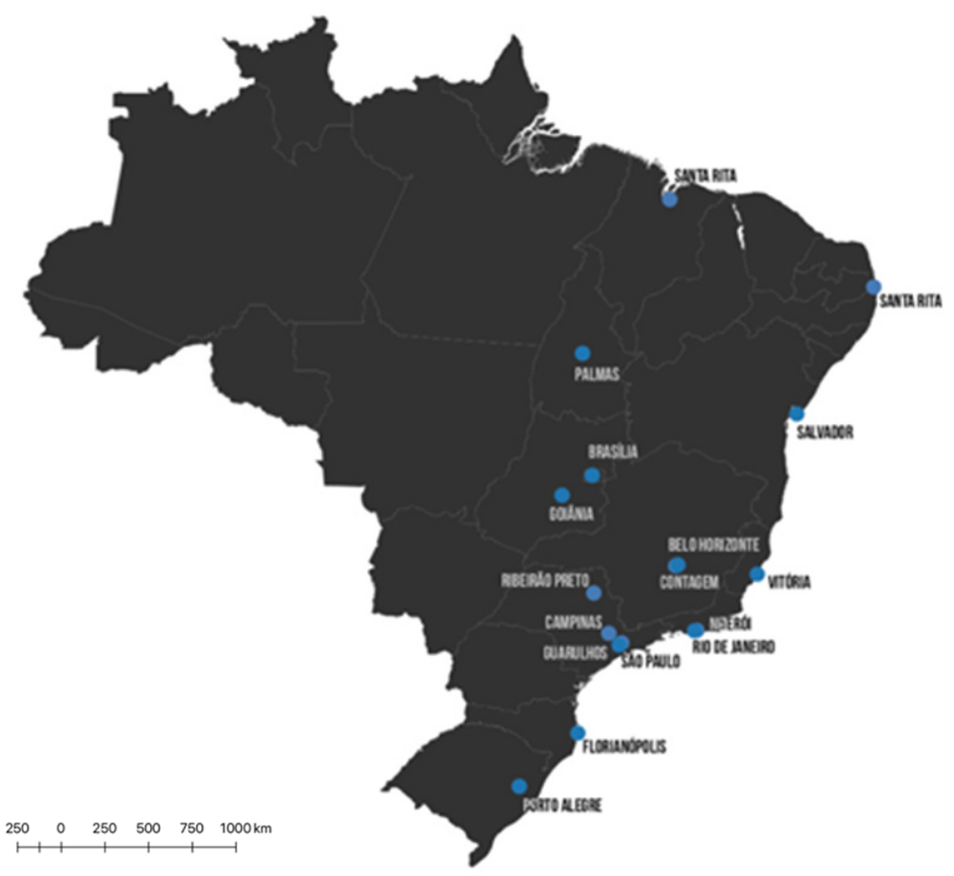


indicar como a hegemonia das formas financeiras predominantes atravessa as ideologias do partido, indicando sua crise. Detectamos, até agora em nossa investigação, uma miríade contendo muitos partidos importantes do País, como é possível observar no Quadro 2.

Quadro 2 - Tabela com relação de empresas municipais de Securitização e Executivo dos respectivos municípios

\begin{tabular}{|c|c|c|c|}
\hline Ano & Entidade para Securitização & $\begin{array}{l}\text { Município } \\
\text { (UF) }\end{array}$ & $\begin{array}{l}\text { Executivo } \\
\text { (Partido) }\end{array}$ \\
\hline 2010 & PBH Ativos & $\begin{array}{l}\text { Belo Horizonte } \\
\text { (MG) }\end{array}$ & $\begin{array}{l}\text { Márcio Lacerda } \\
\text { (PSB) }\end{array}$ \\
\hline 2014 & Permite criar sociedade de propósito específico & $\begin{array}{l}\text { Goiânia } \\
\text { (GO) }\end{array}$ & $\begin{array}{l}\text { Paulo Garcia } \\
\text { (PT) }\end{array}$ \\
\hline 2015 & Companhia Carioca de Securitização & $\begin{array}{l}\text { Rio de Janeiro } \\
\text { (RJ) }\end{array}$ & $\begin{array}{l}\text { Eduardo Paes } \\
\text { (PMDB) }\end{array}$ \\
\hline 2015 & Investe POA & $\begin{array}{l}\text { Porto Alegre } \\
\text { (RS) }\end{array}$ & $\begin{array}{l}\text { José Fortunati } \\
\text { (PDT) }\end{array}$ \\
\hline 2015 & Fundo Especial da Dívida Ativa & $\begin{array}{l}\text { Vitória } \\
\text { (ES) }\end{array}$ & $\begin{array}{l}\text { Luciano Rezende } \\
\text { (PPS) }\end{array}$ \\
\hline 2015 & $\begin{array}{l}\text { Fundo Especial de Créditos Inadimplidos e Dívida Ativa } \\
\text { de Niterói (Fenit) }\end{array}$ & $\begin{array}{l}\text { Niterói } \\
\text { (RJ) }\end{array}$ & $\begin{array}{l}\text { Rodrigo Neves } \\
\text { (PT) }\end{array}$ \\
\hline 2015 & Instituição do Fundo Especial da Dívida Ativa (Feda) & $\begin{array}{l}\text { Santa Rita } \\
\text { (PB) }\end{array}$ & $\begin{array}{l}\text { Reginaldo Pereira da Costa } \\
\text { (PRP) }\end{array}$ \\
\hline 2015 & $\begin{array}{l}\text { Fundo Especial de Créditos Inadimplidos e Dívida Ativa } \\
\text { (Fecidat) }\end{array}$ & $\begin{array}{l}\text { Ribeirão Preto } \\
\text { (SP) }\end{array}$ & $\begin{array}{l}\text { Dárcy da Silva Vera } \\
\text { (PSD) }\end{array}$ \\
\hline 2015 & PMC-Ativos & $\begin{array}{l}\text { Campinas } \\
\text { (SP) }\end{array}$ & $\begin{array}{l}\text { Jonas Donizette } \\
\text { (PSB) }\end{array}$ \\
\hline 2015 & Autoriza a securitização de parte da dívida ativa & $\begin{array}{l}\text { Brasília } \\
\text { (DF) }\end{array}$ & $\begin{array}{l}\text { Rodrigo Rollemberg } \\
\text { (PSB) }\end{array}$ \\
\hline 2016 & Salvador Companhia de Securitização & $\begin{array}{l}\text { Salvador } \\
\text { (BA) }\end{array}$ & $\begin{array}{l}\text { Antônio Carlos Magalhães } \\
\text { Neto (DEM) }\end{array}$ \\
\hline 2016 & $\begin{array}{l}\text { Fundo Especial de Créditos Inadimplidos e Dívida Ativa } \\
\text { de Florianópolis (Fecidaf) }\end{array}$ & $\begin{array}{l}\text { Florianópolis } \\
\text { (SC) }\end{array}$ & $\begin{array}{l}\text { Cesar Souza Jr. } \\
\text { (PSD) }\end{array}$ \\
\hline 2016 & $\begin{array}{l}\text { Fundo Especial de Créditos Inadimplidos e Dívida Ativa } \\
\text { (Fundat) }\end{array}$ & $\begin{array}{l}\text { Guarulhos } \\
\text { (SP) }\end{array}$ & $\begin{array}{l}\text { Sebastião Almeida } \\
\text { (PT) }\end{array}$ \\
\hline 2017 & SP Negócios (altera para permitir securitização) & $\begin{array}{l}\text { São Paulo } \\
\text { (SP) }\end{array}$ & $\begin{array}{l}\text { João Doria } \\
\text { (PSDB) }\end{array}$ \\
\hline 2017 & $\begin{array}{l}\text { Fundo Especial de Créditos Inadimplidos, inscritos } \\
\text { ou não em Dívida Ativa, da Prefeitura Municipal de } \\
\text { Contagem (Fecon) }\end{array}$ & $\begin{array}{l}\text { Contagem } \\
\text { (MG) }\end{array}$ & $\begin{array}{l}\text { Alexis José Ferreira de } \\
\text { Freitas (PSDB) }\end{array}$ \\
\hline
\end{tabular}




\section{Considerações finais}

Políticas públicas são um produto social resultante de uma coalizão de forças que logra ou não efetivar seus interesses no aparato estatal. As políticas públicas tendem a se desenvolver através de diversos meios de mediação social e de interação entre atores em várias escalas e por meio de várias instituições que irão definir o sucesso e a possível difusão de um dado modelo. É possível pensar na criação de políticas públicas como um processo estritamente técnico, mas, na verdade, vemos que policymaking é um processo de interação social entre vários atores para que prevaleçam os seus interesses. Tais interesses sobredeterminam a definição dos desenhos da política. Seguindo um determinado tipo de ideologia, os agentes definem quais são as possíveis meIhores escolhas para guiar uma política pública. Assim, para atender a esses interesses - de várias ordens -, os atores coligam-se para garantir a efetivação e a possível difusão de uma determinada política. Procuramos aqui destacar a importância que atores individuais têm nesse processo: eles acumulam o know-how, fazem o marketing, estabelecem as conexões, viajam e assumem cargos. Tudo isso conforma uma rede de atuação, ou seja, uma coalizão que atua em rede.

No caso, observamos a formação dessa coalizão em torno de uma forma de gestão específica das cidades: o desenvolvimento urbano financiado por meio de mercados financeiros, adotando práticas de securitização com recursos públicos. Percebemos ainda que, para o êxito desse modelo, uma ampla rede de atores mobiliza-se: desde instituições internacionais até membros do poder público e indivíduos.
Aqui, é necessário salientar a importância de acompanhar as ações dessa rede de financeirização das cidades, uma vez que vários impactos desse tipo de medida já são conhecidos, enquanto os ganhos, em geral, parecem se restringir a um grupo muito restrito (Alvarenga, 2018; Fatorelli, 2017; Peck e Whiteside, 2016).

Nota-se que, nesse carrossel da financeirização, os atores circulam por municípios e estados brasileiros, carregando consigo um manual de instruções como panaceia para o contexto de crise fiscal, oferecendo a solução e os meios para aplicá-la, o que, por si só, já explica em grande parte $o$ alastramento desse tipo de medida.

Nossa hipótese é que esse processo de empresificação da política (Canettieri, 2017), com a implementação da securitização do estado, indica um processo único de financiamento das atividades do estado por meio do mercado financeiro que garante o atendimento dos imperativos que são colocados pelo interesse ávido de rendimentos dos capitais portadores de juros. Esse momento pode ser descrito, a nosso ver, como um momento de inflexão na ordem urbana que condiciona o futuro das políticas públicas e compromete a saúde financeira do município, direcionada a ser mobilizada para o pagamento de juros.

Essa inflexão, que chamamos, seguindo a formulação de Ribeiro e Bógus (2018), de inflexão ultraneoliberal, representa um ajuste histórico do padrão de relacionamento do estado em consonância com a natureza rentista-financeira do capitalismo global, que passa a representar o fundamento que direciona e organiza os processos de acumulação. A hegemonia do capital portador de juros foi sendo construída historicamente e é amplamente 
discutida em sua convergência com a esfera produtiva. Acreditamos ser relativamente interessante nos debruçarmos sobre as questões que indicam a convergência das determinações do capital portador de juros que subjugam diretamente o desenho de políticas públicas e a gestão da coisa pública.

Vimos, dessa forma, o relativo sucesso dos agentes envolvidos com a divulgação, a implementação, a coordenação e a continuidade desse tipo de política financeira dos municípios e estados que condiciona a sua saúde financeira, a ser financiada de acordo com os capitais financeiros. Como se sabe, o capital portador de juros é um capital de alta volatilidade, com uma dinâmica acelerada que se direciona a angariar os melhores rendimentos, o que pode passar a sobredeterminar a natureza das políticas públicas que devem ser rentáveis o suficiente para atender às expectativas dos investidores. Não é descabida a hipótese de que os agentes envolvidos possuem interesses específicos com a implementação dessa lógica.

Esse novo formato de política pública, baseada no financiamento do desenvolvimento urbano por meio do mercado financeiro, está em vias de se tornar a regra. A situação de crise fiscal nos municípios, decorrente de uma crise econômica, toma ilusoriamente o discurso neoliberal como uma panaceia. Contudo, essa prática só pode adiar a crise que se acumula, postergando seus efeitos deletérios com a emissão de papéis no mercado financeiro. Mais ainda, esse tipo de política entra em conflito com a tradição de políticas públicas desenvolvidas no Brasil nos últimos anos, que estão sendo sistematicamente desmontadas. Esse cenário coloca um novo contexto para as lutas políticas coletivas.

Vale destacar que o relativo sucesso de sua aplicação não significa que não haja movimentos de consolidação de coalizões contrárias a esse modelo que resistam a essa política. Em Belo Horizonte foi iniciado um movimento contrário à PBH Ativos S/A com a participação de várias entidades sindicais, englobando mandatos do legislativo municipal, movimentos sociais e técnicos, e que conseguiu lograr a abertura de uma Comissão Parlamentar de Inquérito contra a $\mathrm{PBH}$ Ativos S/A. ${ }^{11}$ Ou seja, a reflexão sobre as coalizões a favor da financeirização das cidades também deve levar em conta as várias resistências que surgem nesse processo, disputando os rumos das políticas e de suas escolhas.

\section{[I] http://orcid.org/0000-0003-3662-6104}

Universidade Federal de Minas Gerais, Escola de Arquitetura, Departamento de Urbanismo. Belo Horizonte, MG/Brasil.

thiago.canettieri@gmail.com 


\section{Notas}

(1) Conferir, sobre o golpe: Canettieri (2018).

(2) Utilizamos o termo empresificação da política para designar um processo mais específico do que o empresariamento urbano. Enquanto este tem a ver com um aspecto geral da produção do espaço nas cidades, conforme desenvolvido por Harvey (1996), aquele se refere à adoção de critérios empresariais no desenho das políticas públicas e na forma de seu financiamento, como descrito por Canettieri (2017).

(3) https://www.imf.org/external/np/fad/2003/061103.pdf

(4) https://www.imf.org/en/News/Articles/2015/09/28/04/53/sores092109a

(5) https://www.imf.org/external/pubs/ft/wp/2013/wp13255.pdf

(6) https://www.imf.org/en/News/Articles/2015/09/28/04/53/sopol012915a

(7) Aqui é importante chamar a atenção para a escala. Ela aparece como uma categoria fundamental para entender esses processos. Como demonstram Freitas, Canettieri e Viana (2018) sobre as políticas de neoliberalização, elas circulam em determinadas esferas. Em geral, partem de elaborações gerais que aparecem e se desenvolvem no âmbito internacional, mas sua efetivação acontece, em geral, na escala local do município.

(8) A informação consta da apresentação de Maria Lúcia Fattorelli realizada em Brasília, no Senado Federal, na Audiência Púbica promovida pela Comissão de Direitos Humanos sobre a PLS 204/2016, no dia 12 de setembro de 2016.

(9) Os autores estão "interessados, acima de tudo, nas práticas políticas e sociais que permitem uma mobilidade veloz de determinadas políticas públicas e em quais alinhamentos ideológicos e institucionais facilitam as diferentes viagens e interconexões" (Peck e Theodore, 2015, p. xvi).

(10) Lei n. 10.003/2010 - PBH Ativos S/A (Belo Horizonte, MG); lei n. 9.524/2014 - SPE (Goiânia, GO); lei n. 40.198/2015 - Companhia Carioca de Securitização (Rio de Janeiro, RJ); lei n. 11.991/2015 - Investe POA (Porto Alegre, RS); lei n. 90/2015 - Fundo Especial da Dívida Ativa (Vitória, ES); lei n. 3.173/2015 - Fundo Especial de Créditos Inadimplidos e Dívida Ativa de Niterói (Niterói, RJ); lei n. 1.662/2015 - Feda (Santa Rita, PB); lei n. 2.720/2015 - Fecidaf (Ribeirão Preto, SP); 2015 - PMC Ativos (Campinas, SP); lei n. 23/2015 - Autoriza a securitização de parte da dívida ativa (Brasília, DF); lei n. 8.961/2016 - Salvador Companhia de Securitização (Salvador, BA); lei n. 1.518/2016 - Fecidaf (Florianópolis, SC); lei n. 451/2016 - Fundat (Guarulhos, SP); lei n. 179/2017 - SP Negócios (altera para permitir securitização) (São Paulo, SP); lei n. 221/2017 Fecon (Contagem, MG).

(11) Sobre isso, conferir o artigo de Canettieri, Rena, Sá e Mezzacappa (2018), em que analisam em detalhes os movimentos de resistência contra a PBH Ativos S/A em Belo Horizonte. 


\section{Referências}

AALBERS, M. (2015). "Cities and the financial crisis”. In: WRIGHT, J. D. (org.). The Encyclopedia of Social and Behavioral Sciences. Oxford, Elsevier.

(2016). The potential for financialization. Dialogues in Human Geography, n. 5, v. 2, pp. 214-229.

ALVARENGA, E. (2018). “Democracia em crise: o Brasil contemporâneo”. In: SOUZA, R.; PEZIM, A. M.; ALVES, C. (orgs.). Crise da democracia brasileira. Belo Horizonte, Editora PUC Minas.

BENSON, D.; JORDAN, A. (2011). What have we learned from policy transfer research? Dolowitz and Marsh Revisited. Political Studies Review, n. 9, pp. 366-378.

CANETTIERI, T. (2017). A produção capitalista do espaço e a gestão empresarial da política urbana: o caso da PBH Ativos S/A. Revista Brasileira de Estudos Urbanos e Regionais. Recife, v. 19, n. 3, pp. 513-529.

(2018). Crise do capital e a condição periférica: um ensaio para a interpretação do golpe jurídico-parlamentar no Brasil. Revice - Revista de Ciências do Estado. Belo Horizonte, v. 3, n. 1, pp. 25-36.

CANETTIERI, T.; FRANZONI, J. (2018). "Dívida e gestão pública, o caso da PBH Ativos S/A". In: ROLNIK, R.; SANTORO, P.; MORADO NASCIMENTO, D.; FREITAS, D.; RENA, N.; PEQUENO, L. R. (orgs.). Cidade Estado-Capital: reestruturação urbana e resistências em Belo Horizonte, Fortaleza e São Paulo. São Paulo, FAU-USP.

CANETTIERI, T.; FRANZONI, J.; ROMEIRO, P. (2018). "Reestruturação do Estado-Capital para gestão de PPPs: a criação de empresas de economia mista em Belo Horizonte e São Paulo". In: ROLNIK, R.; SANTORO, P.; MORADO NASCIMENTO, D.; FREITAS, D.; RENA, N.; PEQUENO, L. R. (orgs.). Cidade Estado-Capital: reestruturação urbana e resistências em Belo Horizonte, Fortaleza e São Paulo. São Paulo, FAU-USP.

CANETTIERI, T; RENA, N.; SÁ, S.; MEZZACAPPA, L. (2018). Rede de luta contra a financeirização em Belo Horizonte. In: II SEMINÁRIO INTERNACIONAL URBANISMO BIOPOLÍTICO. Anais... Belo Horizonte, UFMG.

CHRISTOPHERS, B. (2011). Revisiting the urbanization of capital. Annals of the association of American Geographers, v. 101, n. 6, pp. 1347-1364.

CNM - Confederação Nacional dos Municípios (2017). Estudo técnico: a crise fiscal dos municípios. Brasília, CNM.

DARDOT, P.; CLAVAL, C. (2016). A nova razão do mundo: ensaio sobre a sociedade neoliberal. São Paulo, Boitempo.

DOLOWITZ, D.; MARSH, D. (1996). Who learns from whom? A review of the policy transfer literature. Political Studies, n. 44, pp. 343-367.

(2000). Learning from abroad: the role of policy transfer in contemporary policy-making. Governance, n. 13, pp. 5-24. 
FATTORELI, M. L. (2017). O impasse da dívida de estados e municípios. Blog da Auditoria Cidadã da Dívida. Disponível em: https://auditoriacidada.org.br/conteudo/o-impasse-da-divida-deestados-e-municipios/. Acesso em: 7 maio 2018.

FIRJAN - Federação das Indústrias do Rio de Janeiro (2016). Índice Firjan de Gestão Fiscal: ano-base 2015. Rio de Janeiro, Firjan.

FREITAS, D.; CANETTIERI, T.; VIANA, L. (2017). Compreendendo a neoliberalização do espaço a partir de Belo Horizonte: o projeto de extensão BH S/A. Revista Indisciplinar. Belo Horizonte, v. 5, pp. $247-264$.

HAMADA, H. H.; MOREIRA, D.; MILLA, E.; OLIVEIRA, S. (2019). Endividamento público municipal perante a lei de responsabilidade fiscal: uma análise do município de Belo Horizonte no período 2002 a 2017. Revista Conhecimento Contábil, v. 8, n. 1, pp. 25-39.

HARVEY, D. (1996). Do gerenciamento ao empresariamento: a transformação da administração urbana no capitalismo tardio. Espaço e debates, São Paulo, n. 39, pp. 48-64.

(2004). Neoliberalismo: história e implicações. São Paulo, Loyola.

(2013). Os limites do capital. São Paulo, Boitempo.

(2014). O novo imperialismo. São Paulo, Loyola.

(2017). Marx, Capital and the Madness of Economic Reason. Nova York, Verso.

MASSARDIER, G.; POPUEAU, F.; MAYAUX, P.-L.; MERCIER, D.; CORTINAS, J. (2016). Multi-level policy coalitions an interpretative model of water conflicts in the Americas. Ambiente \& Sociedade, v. 19, n. 4.

PBH - Prefeitura Municipal de Belo Horizonte (2010). Lei n. 10.003.

PBH - Prefeitura Municipal de Belo Horizonte (2011). Decreto n. 14.444.

PBH - Prefeitura Municipal de Belo Horizonte (2014). Decreto n. 15.534.

PBH - Prefeitura Municipal de Belo Horizonte (2014). Lei n. 10.699.

PECK, J. (2002). Political economies of scale: fast policy, interscalar relations and neoliberal workfare. Economic Geography, v. 78, n. 3, pp. 331-360.

PECK, J.; THEODORE, N. (2010). Mobilizing policy: models, methods and mutations. Geofurm, v. 41, pp. 169-174.

(2015). Fast policy: experimental statecraft at the thresholds of neoliberalism. Minneapolis, University of Minnesota Press.

PECK, J.; TICKELL, A. (2002). Neoliberalizing Space. Antipode, n. 34, pp. 380-404.

PECK, J.; WHITESIDE, H. (2016). Financializing Detroit. Economic Geography, v. 92, n. 3, pp. $235-268$.

PIERRE, J. (2014). Can urban regimes travel in time and space? Urban regime theory, urban governance theory and comparative urban politics. Urban Affairs Review, v. 26, n. 1, pp. 864-889.

RIBEIRO, L. C. Q.; BÓGUS, L. M. M. (2018). Apresentação do Dossiê: as metrópoles no atual padrão de expansão do capitalismo. Cadernos Metrópole, v. 20, n. 43, pp. 613-623.

STREECK, W. (2018). Tempo comprado: a crise adiada do capitalismo democrático. São Paulo, Boitempo. 
TROAN, A. (2015). After crisis: a marxist take on capital and labor after the financial crisis. e-International Relations. Disponível em: https://www.e-ir.info/2015/11/09/after-crisis-a-marxist-take-oncapital-and-labour-after-the-financial-crisis/. Acesso em: 13 ago 2020.

VAINER, C. (2000). "Pátria, Empresa e Mercadoria. Notas sobre a estratégia discursiva do planejamento estratégico urbano". In: VAINER, C. ARANTES, O.; MARICATO, E. (orgs.). A cidade do pensamento único: desmanchando consensos. Petrópolis, Vozes.

Texto recebido em 5/dez/2018

Texto aprovado em $27 / \mathrm{jul} / 2020$ 
